\title{
Analysis of Performance Management Problems in Catering Industry
}

\author{
Mei Wan ${ }^{1, *}$ \\ ${ }^{1}$ Shandong Vocational College of Science and Technology, Weifang, 261053, China \\ *Corresponding author. Email: $984931171 @$ qq.com
}

\begin{abstract}
With the continuous development of social economy and the continuous improvement of enterprise system, the position of performance evaluation in enterprises is becoming more and more important. How to build a scientific and standardized performance evaluation system suitable for the actual situation of the enterprise on the basis of practice has become a key factor restricting the development of the enterprise. This article uses balanced score card, key performance indicators and other methods to study the performance evaluation system of the small private catering industry. The purpose is to provide a reference for the performance evaluation of the catering industry.
\end{abstract}

Keywords: Performance indicators, evaluation system, balanced score card

\section{INTRODUCTION}

The catering industry is a relatively special industry, and catering enterprises provide both tangible and intangible products. The tangible product is a meal. A meal goes through several processes such as raw material purchase, vegetable selection, vegetable washing, chopping board, lotus. Any error in one process will affect the quality of the dish or the speed of the dish. The head chef is responsible for kitchen management and directly determines the quality of tangible products. Intangible products are dining services. Dining services are becoming more and more important in modern catering activities and directly affect the dining atmosphere. If the service is not enthusiastic, attentive, or even cold-spoken to customers, no matter how good the quality of the food, customers will not be satisfied. So the etiquette and service of the waiter is very important [1]. The role of the dining environment in the dining process should not be underestimated. The clean and hygienic environment and the warm and comfortable atmosphere will allow customers to have a good dining experience. Pre-meal preparation and restaurant layout are also important parts of the entire dining activity. The front office manager is responsible for front office management such as waiter training, pre-meal preparation, restaurant layout, and handling customer complaints, which directly determines the quality of intangible products [2].

\subsection{The Concept of Performance}

There are two explanations for performance. The first is to think that performance is a result, a result for a specific job. The other is that performance is not just a result, but also includes the process or way to achieve this result.
Performance measurement and information feedback refer to the efficiency and completion of achieving the specified goals within the specified time. The foundation of organizational performance is composed of individual performance [3]. However, it is wrong to think that the performance of an individual has nothing to do with the performance of the organization in which it is located or that the organization in which it is located has no performance.

\subsection{Performance Evaluation}

Performance evaluation is a very comprehensive evaluation. Performance evaluation completes the evaluation of performance goals through certain evaluation methods, specified indicators, specified standards, and clear internal implementation channels [4]. When the performance appraisal method was born, it was mainly used to determine the salary and salary of managers, and the scope of application was very small. However, until now, with the enrichment of practice and theory, performance evaluation has been used by more and more organizations as a scientific management tool.

\section{METHODS}

At present, there are many methods adopted by the enterprise performance evaluation system, mainly including the key performance indicator method and the balanced score card.

\subsection{Key Performance Indicators}

Key performance indicators are a type of objective quantitative management indicators that measure process 
performance by setting, sampling, calculating, and analyzing the key parameters of the input and output ends of the organization's internal processes, which is to decompose the strategic goals of the enterprise into operable work. Targeted tools are the foundation of enterprise performance management [5]. KPI can be the head of the department to clarify the main responsibility of the department, and on this basis, clarify the performance measurement indicators of the department personnel. Establishing a clear and practical KPI system is the key to good performance management. Key performance indicators are quantitative indicators used to measure the performance of staff and are an important part of performance planning.

The KPI method conforms to an important management principle-the "Eighth Principle". In the process of value creation of an enterprise, there is the " $80 / 20 "$ rule, that is, $20 \%$ of the key personnel create $80 \%$ of the value of the enterprise; and the "28 principle" applies equally to every employee [6], that is, $80 \%$ Of work tasks are completed by $20 \%$ of key actions. Therefore, we must grasp $20 \%$ of the key behaviors, analyze and measure them, so that we can grasp the focus of performance evaluation.

KPA (Key Process Area) means key process areas. These key process areas indicate the processes that companies need to focus on improving and solving problems. At the same time, these key process areas indicate the specific issues that need to be addressed in order to achieve this capability maturity level. Each KPA clearly lists one or more goals and specifies a set of associated key practices. The implementation of these key practices can achieve the goals of this key process area, thereby achieving the effect of increasing process capability [7]. KRA (Key Result Areas) means the key result area. It is an indispensable area that must achieve satisfactory results in order to achieve the overall goal of the enterprise. It is also the gathering place of the key success factors of the enterprise.

\subsection{Balanced Score Card}

The goals and evaluation indicators in the balanced score card come from the organization strategy, which transforms the organization's mission and strategy into tangible goals and measurement indicators. On the client side of BSC, managers have identified the client and market parts of the organization that will compete, and converted the goals into a set of indicators. Such as market share, customer retention rate, customer acquisition rate, customer satisfaction, customer profitability, etc. In the internal business process of BSC, in order to attract and retain customers in the target market and meet the shareholders' requirements for financial returns, managers need to pay attention to those internal processes that have the greatest impact on customer satisfaction and the achievement of the organization's financial goals. Establish measurement indicators. In this respect, BSC is not focusing on the improvement of the existing business process alone, but on a brand new internal business process that starts with identifying the requirements of customers and shareholders and ending with meeting the requirements of customers and shareholders [8]. The learning and growth aspects of BSC confirm the future investments that the organization must make in order to achieve long-term performance, including the measurement of employees' capabilities and the organization's information system. The success of the organization in the above aspects must be translated into financial success. Improvements in product quality, order completion time, productivity, new product development, and customer satisfaction can only benefit the organization if they are translated into increased sales, reduced operating expenses, and improved asset turnover. Therefore, the financial aspects of BSC set out the financial goals of the organization and measure whether the implementation and execution of the strategy contribute to the improvement of the final operating results. The goals and measurement indicators in the BSC are interrelated [9]. This connection includes not only causality, but also the measurement of results and the measurement of the processes that lead to the results, and ultimately reflects the organizational strategy.

\section{CURRENT SITUATION}

With the continuous expansion of the catering industry and the gradual innovation of business model, the competition in the catering market is increasingly fierce. People's dietary needs began to develop to a higher level. The parallel pattern of multiple business models has become a major feature of the catering market. The coverage rate of catering industry is getting larger and larger, and it has become an indispensable part of people's life. Due to the increasingly prominent integration of the catering industry and various industries, the business model of the catering industry is constantly innovating. In order to meet people's consumption needs, the catering industry has constantly introduced a variety of new business models [10], and adopted a variety of promotional strategies and service concepts. Thus makes the chain operation everywhere, favored by the public. Chain restaurants need to maintain consistent tastes in order to ensure the uniqueness of their brands.

\section{PROBLEM}

\subsection{The Operation Means are Backward}

Now there are a lot of food and beverage industry is still in the stage of manual workshop. Due to price factors, technical factors and other constraints, these catering enterprises cannot achieve large-scale production, production efficiency is very low. At the same time, practitioners are individual workers, their dishes are single production or small batch production, their skills are based on their own experience, there is no opportunity to 
communicate with the outside world, so the production of products technical content is not high, quality is not guaranteed, lack of modern level.

\subsection{Fierce Competition and Lack of Regulations}

The catering industry is an industry with a lower threshold, and it is easy to enter this industry with relatively low capital. At the same time, this industry is also a very risky industry. Due to the low threshold, there will be many industry entrants. The entire catering industry lacks uniform standards and has not set some uniform entry standards. All these will cause the market order of the catering industry to be disrupted. Due to too many competitors, the competition is too fierce, which makes it difficult for this industry to survive. Opening today and closing tomorrow is a very likely event.

\subsection{The Management Level of the Catering Industry is Low}

The management system in the catering industry is still not sound enough. After research and investigation, we found that the quality of existing managers in the catering market is not high, and the quality of employees is relatively low. The management level of the catering industry is relatively low [11]. The industry's management mechanism and the internal management mechanism of the enterprise need to be perfected. Improving the quality of employees has become a top priority.

\subsection{Food safety is Increasingly Concerned by Society}

In recent years, food quality problems have occurred frequently, such as Mad Cow Disease, Clenbuterol Incident, Sudan Red Incident, and Melamine Milk Incident. The food safety situation is worrying. People are paying more and more attention to food safety. In modern society, people are increasingly demanding the quality of food, not only to be full, but also to eat well. The food and beverage industry mainly serves people's daily diet, and consumers pay more attention to the quality assurance of the food and beverage industry. Therefore, the catering industry must guarantee the quality of products and let consumers eliminate worries and worries. Only by allowing consumers to believe and rely on them can they better stand in this industry. Ensuring product quality is the key to the smooth development of the catering industry [12].

\section{CONCLUSION}

The current development status and existing problems of the catering industry will affect the development strategy of the enterprise, and the establishment of the enterprise performance evaluation system must be completed under the strategic guidance. In particular, the private catering industry is relatively small in scale, and the performance evaluation system is not perfect. Combining the advantages and disadvantages of the performance evaluation management method and the actual situation of the private catering industry, the author believes that the KPI analysis method and the balanced score card combined performance evaluation system should be adopted. It is suitable for such enterprises. KPI pays attention to the unity of organizational goals and the goals of departments and employees, which can be more conducive to the realization of strategic goals of the enterprise and make employees pay more attention to key work contents and tasks. It can more efficiently achieve the improvement and rapid development of the company's performance evaluation system; the balanced score card can effectively combine the company's strategic goals with indicators in all dimensions, the evaluation indicator system is more reasonable and comprehensive, and the evaluation goals are more considerable for customers, learning and growth, etc. It is clear and focus on the harmonization of short-term and long-term interests of enterprises. KPI and balanced score card are unified and complement each other, which is more suitable for the development of enterprises.

\section{REFERENCES}

[1] Larry, Sourees of Teehnological Capability in South Area, Technological CaPability in Third World, Edited by M.Fransman and K.King, 1984:163-279.

[2] Freeman, The Economies industrial Innovation, TheMITPress, 1992:131-152.

[3] Burgelman, Strategic Management of Technology and Innovation, New York:Mc Graw-Hill Ine, 1996:23-35.

[4] Zhao Xiaodong, Common problems and solutions in performance management, Technology and Economy, 2006, (2): 91-92.

[5] Shen Zhidong, Using AHP to build a state-owned enterprise performance evaluation system, Audit Research, 2013, 2.

[6] Jie Xiang, Research on the problems and countermeasures of performance management and assessment of SMEs, Economic Management Space, 2012(4): 109-110. 
[7] Xi Menghao, Zhao Lingling, Wang Huiyan, Analysis of performance evaluation methods of state-owned enterprises, Economist, 2007 ( 9), 213-214.

[8] Liu Guofang et al, Construct a scientific market value management performance evaluation system, Board of Directors, 2013(11): 54-55.

[9] Zhao Changhong, Yuan Jiahai. All-round thinking of 360-degree performance evaluation, State Grid, 2007 (2): 64-65.

[10] Ding Junfeng, Tian Jianfang. The Evolution of Subjects and Methods of Enterprise Performance Evaluation, Modern Economic Research, 2005(11): 64-67.

[11] Li Feixia, Wang Jing. Coordination and comparison of employee performance evaluation results in different departments, China Human Resources Development, 2008(6): 46-48.

[12] Qin Jiangbo, Research on performance evaluation system of small and medium-sized enterprises, Jilin University, 2011 (4). 